\title{
El análisis del discurso protocolario: elaboración y conceptualización
}

\author{
Analysis of protocol discourse: production and conceptualization
}

\section{Inmaculada Anaya Revuelta}

Universidad de Vigo, Facultad de Filología y Traducción. Departamento de Lengua Española. Vigo, España. Correo electrónico: ianaya@uvigo.es

\author{
"Hacen falta tres semanas para preparar un \\ discurso improvisado" \\ Marc Twain (1835-1910)
}

Este artículo presenta un estudio de algunos mecanismos lingüísticos que regulan la elaboración del discurso y los efectos conseguidos. Se han examinado cinco discursos pronunciados entre los años 2005 y 2011, pertenecientes a diferentes ámbitos. El propósito es analizar el discurso como un acto lingüístico, exponer los procesos implicados en esta actividad y describir los mecanismos empleados en la construcción del texto. Los resultados indican que el discurso como acto comunicativo es una actividad cognitiva compleja. Los recursos de la lengua y las condiciones socioculturales y psicolingüísticas facilitan al redactor y al receptor las tareas de codificar y descodificar, respectivamente, mensajes coherentes, emotivos y perdurables.

Palabras clave: análisis del discurso, pragmática, contexto socio-cultural, recursos lingüísticos, figuras retóricas.

This article presents a study about several linguistic mechanisms that regulate the production of discourse and the effects achieved. Five discourses which have been delivered between 2005 and 2011 are examined about different areas. Our purpose is to analyse discourse as a linguistic act, to outline the processes involved in this activity and to describe the mechanisms employed in the construction of the text. The results indicate that the discourse, as a communicative act is a complex cognitive activity. The language resources and the sociocultural and psycholinguistic conditions help the writer and the receiver with the tasks of encoding and decoding, respectively, coherent messages, both lasting and emotional.

Key words: Discourse analysis, Pragmatics, sociocultural context, linguistic resources, rhetorical figures

\section{INTRODUCCIÓN}

El Análisis del discurso en los últimos 50 años ha ido perfilando un modelo teórico que aboga por el estudio de la dimensión formal y funcional, representado por la 
pragmática, esto es "el estudio de cómo los enunciados adquieren significado en la situación” (Leech (1997:35). Con importantes aportaciones, algunas de las cuales nos han servido como punto de partida, se ha ido forjando un marco con diferentes principios teóricos, procedentes de otras áreas de conocimiento (sociología, etnografía, psicología, etc.), lo que permite hablar, en cierto modo, de un marco multidisciplinario.

Los estudiosos de este campo han separado los modelos de análisis, grosso modo, en dos grandes líneas: la que distingue la preferencia por el estudio del discurso oral o del escrito; otra línea de investigación sería la que diferencia el análisis de discurso hacia el estudio lingüístico, por un lado, y al social, por otro. Sin embargo, basta con adentrarse en el tema para comprobar que hoy en día estos dos campos constituyen dominios complementarios.

En este trabajo optamos por un modelo de análisis integrador que recoge las teorías más influyentes y, a nuestro juicio, más adecuadas para el análisis de los textos seleccionados, desde una perspectiva lingüística. En este sentido, resulta difícil, a veces, separar los diferentes planos del discurso que se presentan imbricados. Hasta llegar al modelo de análisis que seguiremos, son muchos los que han ido forjando, con sus teorías, diferentes vías de investigación, algunas de las cuales, todavía hoy, resultan útiles. Benveniste (1966) desarrolló la “Teoría de la enunciación”, en la que estudiaba el valor de los deícticos (indicateurs) en el discurso. Estos elementos (pronombres personales, adverbios locativos, etc.) han estado y siguen estando presentes en este tipo de análisis, como veremos más adelante, no tanto desde su sentido gramatical, como desde el valor de su uso en un contexto determinado.

En esta línea de conjugar 'forma’ y ‘función’, John Langshaw Austin (1962), reveló que los enunciados solo reflejan hechos en algunos casos, pero siempre realizan actos. Según este autor, los actos de habla se clasifican en actos locutivos (el acto lingüístico que lleva aparejado un contenido); actos ilocutivos (lo que se hace al hablar) y, por último, los actos perlocutivos (cómo repercute lo dicho en el comportamiento del receptor). Como recuerda Portolés (2004: 171), Austin no pudo desarrollar el concepto de 'acto perlocutivo'; fueron Strawson (1964) y Davis (1980) los que profundizaron, posteriormente, en este tipo de actos. De una manera más sintetizada, Searle (1969) recogió la idea de Austin y completó la teoría con esta idea: el acto de habla es la unidad mínima de comunicación, en la que se unen la fuerza ilocutiva y la forma lingüística.

Halliday y Hasan (1976) centran su estudio en el análisis del discurso escrito y consiguen perfeccionar el marco teórico con una clara exposición sobre la cohesión y los procedimientos encaminados a conseguirla. Algunos de estos procedimientos (sustitución, referencia, conexión léxica y elipsis) son recogidos en el análisis de los discursos que hemos seleccionado.

En otro orden de cosas, y paralelamente a la expansión del Análisis del discurso, el interés por la delimitación o comparación de las modalidades oral y escrita ha ido en aumento. Afirman Cortés y Camacho (2003:66-68) que para los estudiosos, las modalidades oral y escrita revelan diferentes relaciones; los discursos expuestos oralmente tendrían una mayor producción interactiva y los escritos, una mayor producción informativa. Quizás sea un poco exagerada esta valoración, ya que lo oral y lo escrito no constituyen categorías estancas, sino más bien un contínuum con muchos puntos intermedios: textos escritos para ser leídos, textos escritos para ser expuestos de forma oral, etc. 
La escritura, según García y Marbán (2002:13) "es una actividad cognitiva compleja en la que se implican procesos conceptuales, lingüísticos y motores”. Al hablar de la construcción de un discurso, los procesos cognitivos (recogida de información sobre el tema, planificación del mensaje, redacción y revisión del texto) no se pueden aislar de las emociones y estados afectivos del que lo redacta.

El éxito o el fracaso de la elaboración de un buen discurso dependen, en buena parte, de la habilidad del autor para emplear los mecanismos adecuados que regulen la redacción y percepción por parte del receptor. De acuerdo con García y Marbán (2002:43), "los procesos de planificación de un texto se evidencian, principalmente, en la escritura creativa”. En la construcción de un texto intervienen una serie de componentes y procesos de distintos niveles (cognitivo, psicolingüístico, conductual, etc.); de ahí la importancia de explorar la naturaleza de la escritura e intentar desvelar los procesos implicados en dicha actividad.

\section{Metodología y CORpus}

Los discursos objeto de estudio en este trabajo constituyen ejemplos de textos escritos para ser expuestos oralmente en un contexto social elevado. No son, por lo tanto, discursos espontáneos, sino discursos preparados para ser pronunciados ante un auditorio.

Los diferentes enfoques teóricos expuestos contribuyen a orientar la investigación llevada a cabo. En este marco multidisciplinar, nos hemos centrado en el concepto de discurso como acto de habla que se realiza en dos planos: la forma y la función. Leech (1997: 46) basa su argumentación en que la gramática (el sistema formal y abstracto de la legua) y la pragmática (los principios de uso del lenguaje) constituyen dominios complementarios; este autor asocia el concepto de discurso como acto lingüístico a la "superposición de diferentes planos o dimensiones" (plano textual, representacional e interpersonal).

En el análisis de cualquier discurso, el estudioso puede decidirse por un determinado nivel, el lingüístico, el cognitivo y el pragmático, en función de sus objetivos o por más de uno. Para Cortés (2008:30), cualquier análisis del discurso comprende dos tipos de particularidades: los condicionantes y las realizaciones; los primeros van asociados a lo que este autor denomina variación externa y son previos al material discursivo; las realizaciones se asocian con la variación interna, lo escrito. En otro trabajo Cortés (Cortés 2011:7) afirma que los dos tipos de variación se mezclan con los diferentes planos discursivos (plano supraenunciativo, plano secuencial y plano enunciativo). De acuerdo con la teoría planteada por este autor, en este trabajo nos centramos en dos planos de estudio, el secuencial y el enunciativo. El plano secuencial se centra en el análisis de la secuencia, entendida como una unidad del discurso superior al enunciado. En torno a este concepto de secuencia hay diferentes definiciones; aquí partimos de la concepción de ese autor (2011:8), según el cual "las secuencias están formadas por bloques relativamente amplios de enunciados”. Dicho de otra forma, la secuencia responde a la pregunta ¿de qué se está hablando? Por su parte, el plano enunciativo es el que analiza los mecanismos y los efectos que se producen en el discurso; constituye el más tratado por los analistas del discurso. Ambos planos permiten, a su vez, segmentar el análisis en dos niveles: 
El nivel de los condicionantes: el medio, el género, el registro, la relación entre los interlocutores, etc., que nos va a permitir, entre otras cosas, caracterizar los cinco textos protocolares seleccionados.

El nivel de las realizaciones, que corresponde a la producción del discurso y son el resultado de la elección que hace el estudioso entre las posibilidades que ofrece el sistema. Este nivel es el marco en el que se analizan el empleo de las formas lingüísticas y los recursos retóricos, así como los efectos que producen dichas selecciones.

En el análisis de los textos propuestos, segmentamos el discurso en tres partes o secuencias ilocutivas-textuales (plano secuencial) que constituyen las unidades máximas del discurso: secuencia de inicio, secuencia de desarrollo y secuencia de cierre. Cada una de ellas tiene una entidad propia, caracterizada por la homogeneidad y coherencia temática del mensaje.

Cada secuencia, a su vez, está compuesta, por una serie de enunciados, que son las unidades que el hablante escoge dentro del sistema para producir el discurso. En este plano enunciativo, analizamos las herramientas (marcadores del discurso, enumeraciones, repeticiones léxicas, uso de los pronombres personales, modos verbales, etc.) con los que el hablante busca un efecto determinado. Estos efectos pueden ser muy variados, en función de la intención que se persiga: distraer, ordenar, divertir, convencer, enseñar, emocionar, etc.

El corpus de la investigación está compuesto por cinco discursos protocolarios realizados entre los años 2005 y 2011. Los cinco textos se encuentran transcritos en la web en la que se reproducen (Steve Jobs, Vargas Llosa, Ana María Matute, José Blanco y Shakira). Los cinco están sujetos a unas normas, determinadas por el espacio en el que se desarrollan: el tiempo de duración, el tipo de receptor, la finalidad que se persigue, la etiqueta o forma de ir vestidos, los gestos, etc., que permiten agruparlos bajo esta etiqueta de "protocolario". En cuanto al momento de producción, se ha tenido en cuenta que sean discursos pronunciados en la última década; esta es la cronología:

- Steve Jobs ${ }^{1}$ en la Universidad de Stanford (2005)

- Shakira ${ }^{2}$ en la Universidad de Oxford (2009)

- Mario Vargas Llosa ${ }^{3}$ al recibir el Premio Nobel (2010)

- José Blanco ${ }^{4}$ en el Foro de Nueva Economía (2011)

- Ana María Matute ${ }^{5}$ al recibir el Premio Cervantes (2011)

Steve Jobs (San Francisco 1955-2011). Magnate y empresario de los negocios del sector informático y de la industria del entretenimiento en Estados Unidos. Co-fundador y presidente ejecutivo de Apple.

2 Shakira Isabel Mebarak Ripoll (Colombia 1977), cantautora, empresaria y embajadora de la UNICEF. A finales de 1990 creó la "Fundación Pies descalzos" con el fin de ayudar a la población infantil desprotegida.

3 José Mario Pedro Vargas Llosa (Perú, 1936) Es uno de los mejores novelistas y ensayistas contemporáneos. Premio Príncipe de Asturias de las Letras (1986) y Premio Nobel de Literatura (2010).

$4 \quad$ José Blanco (Lugo 1962). Político socialista español. Entre abril de 2008 y diciembre de 2011, ministro de Fomento en el Gobierno de José Luis Rodríguez Zapatero.

5 Ana María Matute (Barcelona 1925). Novelista y miembro de la Real Academia de la Lengua Española (RAE). Es la tercera mujer que ha recibido el Premio Cervantes (2010). 
El tiempo de duración es tenido en cuenta porque cada uno de ellos constituye una unidad de análisis diferente. El criterio de selección seguido en este caso ha sido que los textos seleccionados estuvieran entre 1000 y 7000 palabras. Sin ser determinante, la extensión es un dato más para la caracterización, en cuanto a su extensión. Este es el orden creciente en lo que al número de palabras se refiere:

- Shakira (1200)

- Steve Jobs (2242)

- Ana María Matute (2429)

- José Blanco (2950)

- Mario Vargas Llosa (6157)

En esta selección se han tenido en cuenta otros aspectos. Todos ellos pertenecen a un prototipo de discurso: son escritos para ser pronunciados en situaciones que requieren un protocolo estricto; han tenido cierto impacto social, como demuestran las citas y las reseñas en la prensa, el número de descargas realizadas en la web y los aplausos recibidos, entre otros índices de medición. Estos datos no han sido analizados a fondo en este trabajo, pero lo serán en un estudio posterior. Por otra parte, estos discursos presentan algunas características que permite diferenciarlos, como por ejemplo: pertenecer a cuatro ámbitos distintos de la realidad (la cultura, la política, el mundo empresarial y de los negocios, y el mundo artístico); tratar temas diferentes, dirigirse a públicos distintos, etc.

Los objetivos de este estudio se concretan en dos puntos:

- Explicar qué mecanismos y recursos utiliza el hablante para producir determinados efec tos en el oyente.

- Valorar qué utilidad puede tener este tipo de trabajos en el desarrollo de las competencias lingüístico-discursivas e, incluso, en la formación de los hablantes.

La hipótesis es que existe una relación entre determinadas estrategias discursivas y la recepción exitosa de los discursos.

\section{ANÁLISIS DE LOS TEXTOS. RESULtAdos}

\subsection{Nivel de variación externa: caracterización de los discursos}

Al agrupar bajo una misma etiqueta de "protocolario", los cinco discursos seleccionados, hemos tenido en cuenta los tres niveles antes citados: el lingüístico, el cognitivo y el pragmático. Como afirman Calsamiglia y Tusón (2007: 15), el 'discurso' como acto comunicativo se desarrolla siempre en un marco social determinado: "Hablar de discurso es, ante todo, hablar de una práctica social, de una forma de acción entre las personas que se articula a partir del uso lingüístico contextualizado, ya sea oral o escrito. El discurso es parte de la vida social y, a la vez, un instrumento que crea vida social”.

En este tipo de discursos, el contexto social es determinante, como veremos. Algunas corrientes colaterales al Análisis del discurso, como el coaching y otras actividades relacionadas con la comunicación, han puesto de manifiesto la importancia 
del lenguaje en todo proceso social. Para Echevarría (2011:17) el lenguaje es la clave para poder entender cualquier comportamiento del ser humano: "Lo social, para los seres humanos, se constituye en el lenguaje. Todo fenómeno social es siempre un fenómeno lingüístico".

Camacho (2007) habla de unos 'macrogéneros’ (conversación, interrogatorio, alocución, etc.), cada uno de los cuales comprende unos géneros. Los discursos están dentro del 'macrogénero alocución', junto con las conferencias, las lecciones, etc.

De acuerdo con el modelo, ya citado, de Cortés (2008:23) partimos del concepto de ‘condicionantes funcionales' que son dos: el género y el registro para concretar los rasgos que caracterizan este tipo de discurso. En cuanto al género, estos son los rasgos que lo definen:

El dominio coincide en todos ellos: es 'particular' frente a 'general'.

El grado de complejidad lingüística es en los cinco 'complicado' frente a 'sencillo'.

La estructura en todos los casos es un monólogo, un turno de palabra con límite de tiempo.

El modelo textual es en todos los casos expositivo-argumentativo, si bien, la carga de uno u otro modelo es variable.

La finalidad en este tipo de discursos suele ser emocionar al auditorio, como ocurre en los pronunciados por Steve Jobs, Shakira, Vargas Llosa y Ana María Matute; no así en el discurso de José Blanco donde la eficacia prima sobre la emoción. De acuerdo con la terminología empleada por Cortés, los discursos de Steve Jobs, de Vargas Llosa y de Ana María Matute tendrían una finalidad lúdicoinstructiva, mientras que los de Shakira y José Blanco tienen una finalidad, más bien, efectiva y persuasiva.

En cuanto al registro, los parámetros para determinar el tipo de discurso que analizamos son:

El campo o tema que en los cinco discursos coincide en ser un tema específico, concreto, como ya hemos comentado anteriormente.

El grado de conciencia lingüística, en donde podríamos percibir una pequeña variación de grado, muy sutil, entre alto /formal en los discursos pronunciados por Steve Jobs, Shakira y José Blanco, y muy alto/ muy formal, en los casos, más solemnes, de Vargas Llosa y Ana María Matute.

El grado de formalidad contextual es máximo en los cinco casos, ya que cada uno de ellos se desarrolla en un auditorio o institución de máximo nivel; esta formalidad está sujeta a una serie de normas de comportamiento protocolarias que van, desde la forma de tratamiento a los oyentes, hasta la última palabra y el último gesto realizado.

El grado de regulación de la situación está relacionado con el objetivo que se persigue y con la existencia o no de unas normas que fijen el desarrollo del discurso. En el caso de los cinco discursos, el grado de situación es 'protocolario', hasta el punto de servirnos para agrupar bajo esta denominación, los cinco discursos.

Tanto el tipo de actividad, en todos ellos, presencial, como el nivel de audiencia, institucional, son la consecuencia lógica del grado de formalidad contextual y del grado de regulación de la situación.

En definitiva, estamos ante cinco discursos que pertenecen al 'macrogénero' del discurso oral, y dentro de este, al de la alocución. Como subgénero, se trata de discursos protocolarios que tratan temas diferentes, con un grado de complejidad 
lingüística, una complejidad textual, y una función lúdico-instructiva y persuasiva que los convierte en distintos modelos de un mismo tipo de discurso.

\subsection{Nivel de variación interna: la producción del discurso}

Elaborar un buen discurso no es tarea fácil. Además de encontrar la perfecta correlación entre el plano formal y funcional para que el resultado sea coherente, el discurso tiene que llegar al receptor con la intención que el que lo escribe pretende conseguir en él.

En este nivel analizamos las formas y mecanismos que emplea el hablante con el fin de conseguir unos efectos discursivos concretos. Para conseguirlo, tenemos en cuenta dos planos discursivos: el enunciativo y el secuencial. El plano enunciativo nos ha permitido ordenar las formas e interpretar los recursos lingüísticos que producen, a su vez, unos efectos en el oyente. El plano secuencial abarca los discursos completos y nos permite hablar de las secuencias que se analizan, según un doble criterio: el ilocutivo-textual (inicio, desarrollo y cierre) y la variación temática.

En cada discurso existe un tema principal en torno al cual se desarrolla el discurso:

- Steve Jobs: Hay que reflexionar sobre lo que queremos hacer en la vida y buscarlo hasta encontrarlo

- Shakira: La educación es un derecho para todos

- Mario Vargas Llosa: Hay que leer y soñar

- José Blanco: Defensa de la buena gestión de su Ministerio

- Ana María Matute: El que no inventa no vive

Cada tema se articula en tres partes, secuencia de inicio, secuencia de desarrollo y secuencia de cierre, cada una de las cuales se resume en un sub-tema que guarda una perfecta coherencia con el tema principal. Por ejemplo, en el caso del Steve Jobs, estos son los tres sub-temas:

- Sub-tema 1: Confiar en vosotros mismos, confiar en "conectar los puntos"

- Sub-tema 2: Buscar el amor (en todo) hasta encontrarlo

- Sub-tema 3: Reflexión sobre la muerte

Esta misma división se da en los otros cuatro discursos, por ejemplo, en el de José Blanco:

- Sub-tema 1: Principales logros del último año, a pesar de la oposición

- Sub-tema 2: Problemas que plantea la situación de crisis actual

- Sub-tema 3: Soluciones propuestas por el Gobierno

A la hora de producir un discurso es necesario seguir unas pautas para que este tenga un orden, llegue al oyente y cumpla sus objetivos. Cassany (1995:76) recomienda que la organización quede reflejada en el texto de tal manera que podamos reconocer con claridad el orden en el que se desarrolla el mensaje. No existe un orden lógico o correcto, sino un orden eficaz y coherente. 
La 'coherencia' en un texto implica que el conjunto de ideas y palabras utilizadas para expresar esas ideas guardan una armonía y tienen un sentido global. Según Reyes (2009:127), que un texto tenga coherencia significa que:

1. Su estructura significativa tiene organización lógica y tiene armonía sintáctica, semánti ca y pragmática entre sus partes

2. Su significado es interpretable porque ayuda al lector a hacer las inferencias necesarias.

En opinión de la autora, el primer aspecto se refiere a las conexiones internas del texto: cómo se realizan las relaciones lógicas entre las afirmaciones y cómo se manifiesta la conexión de las partes del texto en los diferentes niveles. La conexión externa del texto con el contexto se refiere a la opción de poder establecer relaciones con otras experiencias conocidas que nos permiten interpretar correctamente el mensaje. Si cualquiera de estos dos tipos de conexión falla, el texto perderá coherencia.

El análisis que corresponde a esta parte de la variación interna o producción del discurso, lo hemos dividido en tres partes: inicio, desarrollo y cierre, que son segmentos paralelos a la temática y que constituyen la proyección ilocutiva-textual de cualquier discurso.

\subsubsection{Secuencia de inicio}

La primera impresión es fundamental porque las primeras impresiones son, casi siempre, las más duraderas. Por eso los dos primeros minutos de cualquier elocución son determinantes.

La fórmula con la que comienza todo discurso es el saludo. En el caso de los discursos protocolarios, lo primero que se suele decir es: "gracias" o "muchas gracias”, en respuesta a las palabras que ha pronunciado la persona que presenta. A continuación, los discursos protocolarios exigen un orden en la enumeración de las personalidades presentes en el acto. Este orden no es arbitrario: está fijado y responde a unas normas protocolarias que cambian poco, en función del acto y de las autoridades.

En el análisis llevado a cabo, hemos comprobado que no existe una fórmula única para comenzar: en cada caso (tema, perfil del hablante, perfil de la audiencia, contexto social, etc.) existe una forma adecuada.

Dos de los cinco discursos analizados, el de Steve Jobs y el de José Blanco, comienzan con el uso de los pronombres personales y un enunciado argumentativo que incluye a todos los oyentes.

Steve Jobs en la Universidad de Stanford: "I am honored to be with you today at your commencement from one of the finest universities in the world". Con estas palabras el efecto discursivo es claro: atraer la atención de todos los estudiantes a los que se dirige con humildad ("I am honored”), y cercanía (uso de los pronombres personales "I”, “we”, “you”; posesivos “your commencement”. Para reforzar este efecto utiliza una expresión rotunda "from one of the finest universities in the world" que contribuye a enfatizar el orgullo que siente de estar en ese lugar con todo el alumnado presente.

Utilizar pronombres que hagan referencia a las personas que participan en el discurso y aludir a la alguna experiencia personal destacada, pone de manifiesto que 
el hablante se dirige a todos y, además, tiene en cuenta y conoce a quién se dirige. El valor de los deícticos en Benveniste ha sido desarrollado posteriormente por otros autores, como Leanne (2009:76). Esta autora pone de manifiesto la eficacia del uso de los pronombres personales en Obama.

El exministro José Blanco empezaba su discurso hablando de “España”, para intentar atraer la atención de todos los oyentes, independientemente de su ideología:

Después de dos años y medio de crisis, España está sedienta, es verdad. Está sedienta de recuperación económica y creación de empleo; sedienta de acuerdos políticos y sociales para luchar contra la crisis; sedienta de dirigentes que piensen en el beneficio del país antes que en su botín electoral. Superar crisis forma parte de la vida. Nadie puede elegir permanecer al margen de los efectos de una crisis familiar, social o económica...

José Blanco apela a un principio común, con una sentencia firme que hace verosímil el discurso: "superar crisis forma parte de la vida”. Con ello involucra a todos los posibles oyentes y les invita a escuchar, ya que en el párrafo anterior recuerda el estado de crisis por el que atraviesa España desde hace dos años y medio (en ese momento, año 2011).

Los buenos oradores saben que aprovechar las experiencias compartidas provoca un efecto de empatía que garantiza la atención. En los discursos protocolarios, en los que se busca producir la efectividad, pero también la emoción, es frecuente que, en esta primera parte, el hablante haga uso de hipérboles (nunca, nadie, todos, etc.); también son frecuentes las alusiones a grandes personalidades de la historia, la cultura o la política (Newton, Churchill). Algunos ejemplos del corpus así lo demuestran:

Steve Jobs: I never ${ }^{6}$ graduated from college. Truth be told, this is the closest I've ever gotten to a college graduation.

Shakira: ¿Cómo es que alguien que nació en Barranquilla, Colombia, ocupa hoy el mismo podio que Newton o Churchill?

Vargas Llosa: Si convocara a este discurso a todos los escritores a los que debo algo o mucho sus sombras nos sumirían en la oscuridad. Son innumerables.

José Blanco: Nadie puede elegir permanecer al margen de los efectos de una crisis.. .

Ana María Matute: Sospecho que no soy la primera en decir que nunca, durante la larga travesía de mi vida (salpicada, por cierto, de abundantes tempestades), imaginé que llegara a conocer un día como este.

Los efectos discursivos, en este caso, son la eficacia, y conseguir despertar interés en el oyente. En todos los casos analizados, el hablante comienza buscando un punto de encuentro con el oyente, a veces, de impacto, que garantiza la atención. Este punto de encuentro puede lograrse, convirtiéndose en un participante más de la ceremonia de Graduación, como ocurre en el caso de Steve Jobs. Shakira, por su parte, busca esa conexión en una alusión a su faceta de artista, que es la que le hace ser conocida para ese público al que se va a dirigir; por último, Vargas Llosa empieza su discurso, de una forma peculiar, recordando un hecho en su vida tan importante como común a muchos de los presentes en ese acto: cuándo aprendió a leer y quién le enseñó. Todos ellos persiguen el mismo objetivo: conseguir la empatía del público.

El uso de la negrita es nuestra 
Steve Jobs: I am honored to be with you today at your commencement from one of the finest universities in the world.

Shakira: Es para mí un verdadero honor y privilegio estar aquí con ustedes. La verdad es que estoy un poco perpleja, ya que hoy no voy a cantar ni a mover las caderas.

Vargas Llosa: Aprendí a leer a los cinco años, en la clase del hermano Justiniano, en el Colegio de la Salle, en Cochabamba (Bolivia). Es la cosa más importante que me ha pasado en la vida

En la secuencia de inicio, al igual que en las otras dos posteriores, los 'marcadores del discurso' son formas habituales e imprescindibles, ya que su uso facilita la comprensión del texto y refuerza la coherencia y la claridad del mismo. Los marcadores del discurso son formas que guían al lector para que pueda inferir qué sentido adquieren las palabras que van a continuación. Son, sin duda, elementos clave en el desarrollo de las ideas. Portolés (2004:86), afirma que, en este modelo inferencial, el hablante proporciona un estímulo ostensivo para llegar a un determinado sentido; este sentido es inferido por los receptores a partir de dicho estímulo. Por otra parte, Montolío (2001:21) incide en la idea de que estos elementos son claves para conseguir una mayor claridad: "Los conectores funcionan en un texto como señales de balizamiento que un escritor eficaz va distribuyendo a lo largo de su discurso, a fin de que su lector siga, sin esfuerzos ni dificultades, el camino interpretativo trazado".

El uso de los 'marcadores del discurso' o 'conectores' ayuda, no solo a organizar las ideas, sino también, a enfocar adecuadamente el sentido de los distintos apartados del discurso y a darles cohesión. Sanz Álava (2007:30-33) afirma que "la cohesión está basada en la repetición de elementos léxicos y gramaticales y esta se manifiesta, entre otras formas, con el uso de los marcadores del discurso"?

En la secuencia de inicio de los discursos analizados, hemos seleccionado tres casos para el análisis de los marcadores: el de Ana María Matute que utiliza ocho marcadores discursivos en una secuencia de 154 palabras (5\%); el de Vargas Llosa que utiliza cuatro marcadores en 114 palabras (3,5\%); y el de Shakira que solo emplea un marcador en 146 palabras.

Ana María Matute: Sospecho que no soy la primera en decir que nunca, durante la larga travesía de mi vida (salpicada, por cierto, de abundantes tempestades), imaginé que llegara a conocer un día como este. $\mathbf{Y}$, junto a la inmensa alegría que me invade, debo confesarles que preferiría escribir tres novelas seguidas y veinticinco cuentos, sin respiro, a tener que pronunciar un discurso, por modesto que éste sea. $\mathbf{Y}$ no es que menosprecie los discursos: sólo los temo. Mi incapacidad para ellos quedará manifiesta enseguida, $y$, por tanto, me permito apelar a su benevolencia. Pero antes deseo hacerles partícipes de mi agradecimiento: este premio lo considero como el reconocimiento, ya que no a un mérito, al menos a la voluntad y amor que me han llevado a entregar toda mi vida a esta dedicación.

Así que esta anciana que no sabe escribir discursos, solo desea hacerles partícipes de su emoción, de su alegría y de su felicidad...

El uso de por cierto aclara y concreta lo dicho anteriormente; la conjunción y al comienzo de dos de las frases tiene la función de conectar una frase con la anterior.

Esta autora recoge en forma de cuadro sinóptico los marcadores del discurso, tal y como los clasifican en 1999 Martín Zorraquino y Portolés, y los marcadores discursivos orales de Montserrat Vila (2000). 
El uso de la expresión al menos le sirve para matizar la afirmación del comienzo. Para estructurar las ideas, la hablante emplea ya que, un conector que indica 'causa', y otros dos, por tanto y así que que indican 'consecuencia’ y, por último, el empleo de pero introduce un cambio de dirección en el discurso: "pero [...] antes de [...] deseo [...]"

Vargas Llosa: Pero estas dudas nunca asfixiaron mi vocación y seguí siempre escribiendo, incluso en aquellos períodos en que los trabajos alimenticios absorbían casi todo mi tiempo. Creo que hice lo justo, pues, si para que la literatura florezca en una sociedad fuera requisito alcanzar primero la alta cultura, la libertad, la prosperidad y la justicia, ella no hubiera existido nunca. Por el contrario, gracias a la literatura, a las conciencias que formó, a los deseos y anhelos que inspiró, al desencanto de lo real con que volvemos del viaje a una bella fantasía, la civilización es ahora menos cruel que cuando los contadores de cuentos comenzaron a humanizar la vida con sus fábulas.

El ‘conector contra-argumentativo’ pero atenúa la afirmación anterior (“me pregunté [...] si escribir no era un lujo solipsista”). Los 'conectores aditivos’ incluso y ‘consecutivo’ pues consiguen el efecto discursivo de una buena ordenación lógica y eficaz. Otro 'contra-argumentativo' por el contrario consigue que el oyente capte un cambio de argumentación en el discurso, antes de escuchar el argumento que sigue a continuación.

Por último, analizamos la secuencia de inicio en el discurso de Shakira. El hecho de que solo aparezca un marcador del discurso en un periodo de 146 palabras puede producir la sensación de que falta algún elemento que facilite la lectura y dé unidad a las distintas partes del fragmento.

Shakira: Es para mí un verdadero honor y privilegio estar aquí con ustedes. La verdad es que estoy un poco perpleja, ya que hoy no voy a cantar ni a mover las caderas.

¿Cómo es que alguien que nació en Barranquilla (Colombia) ocupa hoy el mismo podio que Newton o Churchill? ¡Dios sabe que no soy la Madre Teresa...! Pero aquí estoy con ustedes.

Me doy cuenta de que el mejor punto de partida que tengo para dirigirme a ustedes es como artista. Nosotros, los artistas, dependemos de nuestra imaginación. Cuando me dijeron que yo estaría aquí, pensé en el pasado e imaginé el futuro.

La ausencia de marcadores es sustituida, en este caso, por otro mecanismo que busca una finalidad distinta. En el vídeo en el que se reproduce la emisión del discurso, se aprecia el efecto perlocutivo que tiene la frase: "La verdad es que estoy un poco perpleja, ya que hoy no voy a cantar ni a mover las caderas"; esta secuencia va acompañada de gestos que evidencian una actitud coqueta por parte de la hablante que sabe que gusta a su público, especialmente, por esa acción. La cantante se encuentra en un escenario muy diferente al habitual para ella, un aula de la Universidad de Oxford; con este acto ilocutivo consigue que el público asistente, jóvenes estudiantes, corten el discurso para expresar 'disgusto', ‘falsa decepción’ (se oye “¡ooooh!”), e interrumpan con un fuerte aplauso.

En resumen, Ana María Matute es la que emplea un mayor número de marcadores en la secuencia de inicio, mientras que en la secuencia de desarrollo, como veremos más adelante, es José Blanco el que emplea este recurso con más intensidad. 
Además de los marcadores del discurso la coherencia del texto está garantizada por otras formas, como las series enumerativa que aportan al texto claridad; este mecanismo resulta muy adecuado para enfatizar. Entre los cinco discursos analizados, dos de ellos emplean la enumeración como recurso para buscar la claridad y la efectividad, en la secuencia de inicio: el de Steve Jobs y el de José Blanco.

Steve Jobs: Today I want to tell you three stories from my life. That's it. No big deal. Just three stories. The first story is about connecting the dots [...] My second story is about love and loss [...] My third story is about death.

En el ámbito de los 'discursos protocolarios' existen diferentes posturas sobre la conveniencia o no de enumerar las distintas partes. Shel Lane (2009:71-74) afirma que, cuando lo que se persigue es influir en corazones y en mentes, el formato de la enumeración puede provocar que la charla se perciba como más seria y distante, ausente de emoción. En su opinión, la enumeración imprime al discurso una formalidad que puede estar reñida con la emoción. En nuestra opinión, esta afirmación debe ser matizada, ya que enumerar las partes al comienzo de un discurso, no siempre tiene por qué restar emoción al mismo; prueba de ello es el tono emotivo de las palabras de Steve Jobs.

Por otra parte, en entornos más formales, como la empresa o los foros, enumerar las partes en la secuencia de inicio puede resultar un recurso muy eficaz. Sirva como ejemplo el discurso que el exministro José Blanco pronunció en el Forum de Nueva Economía, el 11 de enero de 2011. En esa ocasión hizo uso de la enumeración, con pocas cifras, bien planteadas, y habló, por ejemplo, de la 'cuenta de resultados':

- 391 millones más de toneladas de mercancía a través de nuestros puertos

- 193 millones de pasajeros en nuestros aeropuertos

- 16 millones de pasajeros en Alta Velocidad

En este mismo discurso, enumeró, también, los objetivos y las dificultades a las que se habían tenido que enfrentar. La enumeración puede ir precedida o no del número de ítems que forman la enumeración:

- Las mayores nevadas de las últimas décadas

- La nube de cenizas que paralizó el espacio aéreo europeo bajo presidencia española

- El ajuste presupuestario más severo de todos los departamentos del gobierno

- El envite de los controladores aéreos

Sobre este mecanismo textual de gran implicación cognitiva, Estrella Montolío (2006:248) ha realizado un interesante estudio, aplicado, en este caso, a documentos técnicos, pero que resulta extensible en sus conclusiones a cualquier otro tipo de texto: "La enumeración es un mecanismo lingüístico cuyo uso competente incide de una manera decisiva en la mejora de la calidad y productividad de las tareas de elaboración de documentos técnicos y, en general, en los procesos de comunicación y gestión del conocimiento”.

Montolío (2006:255) habla de la utilidad de esta forma por su alto valor predictivo. La 'enumeración', bien empleada, contribuye a organizar bien el contenido y, constituye una ayuda inestimable en el proceso de descifrar el sentido de un texto. 
Entre los mecanismos que pueden ser utilizados en la secuencia de inicio se encuentran también los recursos retóricos. Este tipo de formas se utiliza con un efecto perlocutivo claro: conseguir mover el ánimo de los que escuchan. José Blanco comienza su discurso con estas palabras: "España está sedienta, es verdad. Está sedienta de recuperación económica y de creación de empleo; sedienta de acuerdos políticos y sociales para luchar contra la crisis; sedienta de dirigentes que piensen en el beneficio del país antes que en su botín electoral".

El día anterior, Mariano Rajoy ${ }^{8}$, entonces, jefe de la oposición, había pronunciado estas palabras: “España tiene sed de elecciones”. Blanco recoge esta expresión final de su oponente para empezar su discurso. Este recurso es conocido como 'conduplicación'. La efectividad del recurso se ve reforzada con otra figura retórica, la 'anáfora' (repetir una o más palabras al comienzo de varias oraciones). La repetición del adjetivo "sedienta" contribuye a enfatizar, es decir, a dar a entender con fuerza y entusiasmo lo que se expresa.

En el plano enunciativo, una frase como "España está sedienta de recuperación económica y de creación de empleo”, tiene dos efectos discursivos. Como acto ilocutivo el sentido sería: 'advertir'; el acto perlocutivo comprende todas las reacciones que puedan provocar estas palabras en el oyente: preocupación, deseo de recuperación, confianza/ desconfianza en sus dirigentes, etc.

En el siguiente cuadro recogemos, de forma sintetizada, los principales recursos utilizados en la secuencia de inicio y los efectos conseguidos ${ }^{9}$.

Tabla 1. Recursos y efectos en la secuencia de inicio

\begin{tabular}{|l|l|l|}
\hline \multicolumn{1}{|c|}{ DISCURSO } & \multicolumn{1}{|c|}{ RECURSOS } & \multicolumn{1}{c|}{ EFECTOS } \\
\hline SJ, JB & $\begin{array}{l}\text { Pronombres personales } \\
\text { Enunciados argumentativos }\end{array}$ & $\begin{array}{l}\text { Cercanía, eficacia } \\
\text { Atraer la atención } \\
\text { Influir }\end{array}$ \\
\hline SJ, SH, MV, JB, AM & $\begin{array}{l}\text { Palabras y expresiones asociadas a realidades } \\
\text { extremas (nunca, nadie...) }\end{array}$ & $\begin{array}{l}\text { Emoción, interés, intriga, } \\
\text { atención, efectividad }\end{array}$ \\
\hline JB, SH, MV & $\begin{array}{l}\text { Enunciados que se refieren a una realidad } \\
\text { compartida, un punto en común }\end{array}$ & $\begin{array}{l}\text { Empatía, familiaridad, agrado, } \\
\text { complicidad }\end{array}$ \\
\hline SH, VL, AM & $\begin{array}{l}\text { Marcadores del discurso (por cierto, por tanto, } \\
\text { pero, ya que, así que, pues, por el contrario, } \\
\text { y...) }\end{array}$ & $\begin{array}{l}\text { Claridad, coherencia, unidad, } \\
\text { orden }\end{array}$ \\
\hline SJ, JB & Series enumerativas & Efectividad, claridad, orden \\
\hline JB & Figuras retóricas (anáfora, conduplicación) & Eficacia, claridad \\
\hline
\end{tabular}

\subsubsection{Secuencia de desarrollo}

De acuerdo con la teoría que postula la ontología del lenguaje, defendida, entre otros, por el citado, Rafael Echevarría, no se trata solo de que la lengua nos permita

$8 \quad$ Mariano Rajoy (Santiago de Compostela, 1955). Presidente del Gobierno de España desde diciembre de 2011 y Presidente del Partido Popular. Fue líder de la oposición parlamentaria durante los mandatos de 2004-2008 y 20082011, durante el Gobierno de José Luis Rodríguez Zapatero.

$9 \quad$ En las tablas aparecen las iniciales de los realizadores de los discursos: Steve Jobs (SJ), Shakira (SH), Mario Vargas Llosa (MV), José Blanco (JB) y Ana María Matute (AM). 
construir mensajes correctos y hablar de ciertos temas; la lengua, además, puede provocar que sucedan cosas. Recordemos que Austin, en el año 1962 ya había titulado un libro con esta idea: “Cómo hacer cosas con palabras”. La palabra, bien utilizada, puede despertar y mover emociones.

Para comunicar es imprescindible saber llegar a las emociones del que escucha. El valor perlocutivo del discurso implica reacciones que pueden ser muy diferentes, en función de la realidad de cada oyente. Para conseguir este objetivo, es necesario que la estructura del discurso esté bien planteada y se adecúe al oyente. La estructura de las ideas -vayan enumeradas o no- debe quedar reflejada en una sintaxis clara y ordenada. En el plano de la organización, como señala Cassany (1995:76) "las divisiones y subdivisiones de nuestro esquema tienen que corresponderse con unidades equivalentes en el texto".

Generalmente, y así ocurre en los cinco discursos analizados, la parte que corresponde a la secuencia de desarrollo suele ser la más extensa. Es aquí donde se exponen los argumentos, se citan ejemplos, se crean imágenes, etc., que hacen comprender mejor el mensaje. Utilizar mecanismos que favorezcan la coherencia facilita y asegura la interpretación del texto como un plan global, con un objetivo único. Al ser esta la parte más extensa del discurso, hemos optado por centrarnos, principalmente, en uno, el de José Blanco, que es muy representativo, ya que recoge todos los recursos que aparecen el resto de los textos analizados. El único recurso que no aparece en este texto y sí en otros es el de las preguntas retóricas, que aparecen en el de Vargas Llosa y, sobre todo, en el de Shakira, motivo por el cual, este mecanismo lo trataremos aparte.

Una de las claves de este sentido único que debe tener todo el discurso está en el enunciado que indica el paso de una secuencia (inicio) a otra (desarrollo). En el texto de José Blanco esta secuencia se inicia del modo siguiente: "Pero no siempre las cosas salen como queremos, o tan rápido como queremos, y a veces cometemos errores".

Empieza la secuencia de desarrollo con una contra-argumentación pero, que tiene la función de unir dos partes: la referida a sus resultados en el Ministerio y la que explica su manera de afrontar la situación actual de crisis. En esta segunda parte, que es la del desarrollo propiamente dicho, aparecen varios mecanismos que persiguen un efecto discursivo eficaz, como son los 'mecanismos de modalización' (Cortés 2008:38), palabras y expresiones enfáticas, encaminadas a expresar contundencia.

España es un claro ejemplo. Cuando gobiernan los conservadores, todo es un milagro. Y cuando están en la oposición todo es un desastre. El pesimismo no es inocuo. Y tampoco surge espontáneamente. Es un instrumento de control social que no sirve para crear nada, pero que tiene una utilidad antipolítica: diluir las conexiones entre los ciudadanos.

Si las cosas sólo pueden empeorar, de nada sirve unirnos para que mejoren. Si los resultados jamás podrán ser positivos, de nada sirve intentarlo. Esa es la lógica del relato pesimista. Un relato corrosivo económicamente. Genera desconfianza. Desincentiva el consumo, y desmotiva al emprendimiento.

Con cierta frecuencia, suele haber alguien que, amablemente, se acerca para decirme que este Gobierno ha tenido la mala suerte, de tener que enfrentarse a una crisis económica tan dura. Y siempre respondo lo mismo. En un momento como este, tan decisivo para España, cualquier progresista prefiere que su partido esté en el Gobierno y no en la oposición. 
Otro recurso importante es la repetición de formas que también aparece, como hemos visto, en la secuencia de inicio. En este caso, la repetición de elementos se da al comienzo del enunciado y al final. En retórica, la repetición de las mismas palabras al comienzo se conoce como 'anáfora' y la repetición al final de varias frases seguidas como 'epífora’ (Rodríguez et al. 2005: 218); son dos recursos eficaces para centrar la atención del oyente.

Cuando se habla de empleo, no basta con decir que hay que reducir el número de desempleados. Hay que decir cómo.

Cuando se habla de pensiones, no basta con decir que hay que garantizarlas. Hay que decir cómo.

Cuando se habla de recortar más el gasto público. Hay que tener el coraje y el compromiso democrático para decir dónde se recorta y cómo se recorta.

En esta parte del discurso de José Blanco encontramos, también, 'mecanismos de (des)cortesía institucionalizada’ (Cortés 2008:37), en las dos direcciones que rigen estos mecanismos: estrategias para crear una imagen negativa del rival y la creación de la autoimagen positiva.

En el caso del enunciado empleado para crear una imagen negativa del rival, el hablante hace uso del adjetivo claro para definir el estado de la cuestión. El paralelismo que establece entre su oponente (los conservadores) y ellos (el gobierno) queda reflejado en el uso de las expresiones opuestas como "todo es un milagro"/ "todos es un desastre":

España es un claro ejemplo. Cuando gobiernan los conservadores, todo es un milagro. Y cuando están en la oposición todo es un desastre. El pesimismo no es inocuo.

En el caso de las estrategias para crear una autoimagen positiva, vuelve a aparecer el adjetivo claro, que se repite con el femenino clara, para explicar la actitud positiva y eficaz de los suyos:

El mensaje del Gobierno es claro: nuestras reformas tienen una orientación clara para responder a los desafíos del futuro: reforzar nuestro estado de bienestar, estimular la competitividad de las empresas y garantizar la sostenibilidad de las cuentas públicas. Hacemos reformas para que el estado de bienestar no sea un recuerdo del siglo XX, sino el eje vertebrador del siglo XXI.

Este tipo de recursos es frecuente en discursos políticos, como también lo son el uso de los pronombres personales, especialmente, el uso enfático del pronombre personal de primera persona del singular yo y de los demostrativos e indefinidos que incluyen al interlocutor, como se refleja en las palabras del exministro:

Yo ejerzo mi responsabilidad pública bajo estas premisas. Sé que trabajamos sobre realidades complejas, que no siempre es fácil acertar, y que la inversión más segura de todas es la que hacemos al proyectar nuestro propio esfuerzo, sin dejarnos llevar por el pesimismo.

Todos tenemos tarea en esto. Todos podemos predicar con el ejemplo. En el Ministerio de Fomento hemos aprobado una orden para mejorar la eficiencia de todas las actuaciones para la construcción de infraestructuras. [...] Todas las administraciones del Estado deben mejorar su eficiencia. Todos debemos cumplir con el objetivo de déficit:. 
A lo largo de la secuencia de desarrollo, José Blanco hace uso de algunos marcadores que, además de dar coherencia a la secuencia, ayudan a entender con más claridad el mensaje. Aparece 9 veces el ‘conector contraargumentativo’ pero y una vez sin embargo:

Pero no siempre las cosas salen como queremos.

Pero sólo cuando uno cree en lo que hace, y en por qué lo hace, y cuando se actúa con determinación se pueden superar las dificultades y aspirar a encarar nuevos retos.

No lo negaré. Pero sí quiero precisar que esa intensidad guarda relación con quien esté en el poder.

Son cambios que pueden encontrar resistencias de corte corporativista, pero que merece la pena llevar acometer $[\ldots]$

Pero solo transferiremos al sector privado la gestión, si éste demuestra que es capaz de ser más eficiente, que una gestión directa de AENA.

Pero la determinación no es el único elemento decisivo.

[...] Intuitivamente, asociamos la supervivencia con la capacidad de adaptación al medio.

Sin embargo, como la ciencia ha demostrado, quienes sobreviven no son los más fuertes, sino los más capaces de cooperar.

Pero el combate de la crisis no lo puede hacer solo la Administración General del Estado.

Pero, todavía, no todos han interiorizado que la escala de cada crisis, es proporcional a los cambios económicos, sociales y culturales, que genera su superación. España es un buen ejemplo de ello.

Fue, sobre todo, una época de cambio de régimen político. Pero también de reformas cruciales en el ámbito socio-económico. Muchas de ellas fueron muy difíciles e impopulares.

Los 'conectores contra-argumentativos' pero y sin embargo desvían la argumentación que le precede en la frase anterior y encabezan un razonamiento que contrasta con lo anterior. Esta intención responde al propósito del hablante de hacer ver al oyente su postura y las dificultades que conlleva la situación actual.

También aparece con cierta frecuencia por eso (seis veces), por esta razón (una vez), y así (dos veces), marcadores consecutivos que denotan que lo dicho en el enunciado que le sigue, se deduce del argumento que le precede.

Por eso ayer mismo la Vicepresidenta Segunda, anunció un plan para el fortalecimiento del sistema financiero, con el objetivo de reforzar su credibilidad y permitir que fluya el crédito a las empresas.

Por eso la cooperación, la capacidad de colaboración internacional y de llegar a acuerdos en el ámbito del Estado, es un factor decisivo en la acción política del Gobierno de España. Por eso cuando se dice que queremos abaratar el despido, se está señalando precisamente lo contrario de lo que persigue el gobierno.

Y así en 2009, mientras los precios bajaban y los salarios subían un 3,2\%, se destruyeron 1.200 .000 empleos

Así en el ámbito del transporte, además de la clásica actividad inversora del ministerio de Fomento, también estamos actuando sobre la regulación que permita aumentar la liberalización en el sector y mejorar su competitividad, eliminando barreras administrativas. Por eso vamos a facilitar la gestión a empresas privadas de los grandes aeropuertos por medio de concesiones.

Por eso nuestro empeño en incluir a empresarios y sindicatos en esta tarea.

Por eso la cooperación, la capacidad de colaboración internacional y de llegar a acuerdos 
en el ámbito del Estado, es un factor decisivo en la acción política del Gobierno de España.

Por eso nuestro empeño en incluir a empresarios y sindicatos en esta tarea.

Estos son los más representativos en esta parte del discurso, en la que aparecen otros, con menor frecuencia como: en realidad y de hecho que son 'operadores de refuerzo argumentativo’ que transmiten seguridad por parte del hablante. Esto genera un efecto de confianza en el oyente, muy importante en los discursos políticos, como el que estamos analizando:

En realidad, solo reforma y moderniza su país con ambición quien cree en él y en sus posibilidades de futuro.

Tampoco les ha ido mal a EEUU, Alemania o Canadá, estados tan descentralizados como el nuestro. De hecho, sin el modelo autonómico del que nos hemos dotado, sería impensable haber alcanzado, en tan poco tiempo, el grado de progreso, bienestar y cohesión territorial actual.

Este análisis de la secuencia de desarrollo en el discurso de José Blanco se resume en el siguiente cuadro.

Tabla 2. Secuencia de desarrollo en el discurso de José Blanco

\begin{tabular}{|l|l|}
\hline \multicolumn{1}{|c|}{ RECURSOS } & \multicolumn{1}{|c|}{ EFECTOS } \\
\hline $\begin{array}{l}\text { Marcadores discursivos para enlazar con la } \\
\text { secuencia anterior }\end{array}$ & Unidad, eficacia, claridad \\
\hline $\begin{array}{l}\text { Marcadores discursivos para disentir, expresar } \\
\text { consecuencias, reforzar argumentos }\end{array}$ & $\begin{array}{l}\text { Oposición, advertencia; credibilidad, coherencia; } \\
\text { seguridad, confianza }\end{array}$ \\
\hline $\begin{array}{l}\text { Repetición de palabras y expresiones } \\
\text { sintácticas }\end{array}$ & Eficacia, énfasis \\
\hline $\begin{array}{l}\text { Mecanismos de (des)cortesía institucionalizada } \\
\text { (palabras que reafirman lo positivo de la gestión } \\
\text { del que habla y lo negativo del contrario) }\end{array}$ & $\begin{array}{l}\text { Admiración, confianza, seguridad; rechazo, } \\
\text { desconfianza, inseguridad. }\end{array}$ \\
\hline $\begin{array}{l}\text { Pronombres personales e indefinidos incluyentes } \\
\text { (yo, todos) }\end{array}$ & Énfasis, cercanía, implicación \\
\hline Figuras retóricas (anáfora, epífora, metáfora...) & Eficacia, claridad, efectividad, énfasis \\
\hline
\end{tabular}

Entre los mecanismos que añaden emotividad y eficacia en esta secuencia de desarrollo ocupan un lugar destacado las figuras retóricas. Ya hemos comentado la presencia de algunas figuras ('anáfora' y 'epífora'), en la secuencia de inicio, basadas en la repetición, fenómeno importante desde el punto de vista de la coherencia, ya que facilita la relación interactiva con el oyente. Esta estructura de repetición aparece también en el discurso de Steve Jobs: "So you have to trust that the dots will somehow connect in you future. You have to trust in something: you gut, destiny, life, karma, whatever. Because believe in the dot connect down the road will give you the confidence to follow your heart..."

Entre las figuras retóricas, es probable que no exista una figura más empleada por los hablantes que la ‘metáfora'. Está demostrado que la mente cuenta con un componente imaginativo que nos permite conectar una realidad con otra, eliminar barreras y acortar distancias que generan, casi siempre, claridad en la exposición. Se puede decir que es 
un recurso eficaz para dar a conocer lo que queremos transmitir. En los cinco discursos analizados hay abundantes ejemplos, entre los que hemos seleccionado los siguientes:

Steve Jobs: Sometimes life hits you in the head with a brick [...] And that is as it should be, because Death is very likely the single best invention of Life. It is Life's change agent. José Blanco: España está sedienta de recuperación económica y de creación de empleo. Ana María Matute: Y traigo esto a cuento para explicar -y quizá explicarme de algún modomi extrañeza, mi entrega total, absoluta, a esto que luego supe se llamaba Literatura. Y que ha sido, y es, el faro salvador de muchas de mis tormentas.

Vargas Llosa: Desde entonces y hasta ahora, en todas las circustancias en que me he sentido abatido o golpeado, a orillas de la desesperación, entregarme en cuerpo y alma a mi trabajo de fabulador ha sido la luz que señala la salida del túnel, la tabla de salvación que lleva al náufrago a la playa.

Otro de los recursos retóricos encaminados a conseguir la cohesión del texto son las preguntas retóricas. Solo en dos de los discursos analizados, aparece este mecanismo, utilizado en proporción muy diferente, según los casos. En Vargas Llosa, lo encontramos una sola vez. En cambio, en el discurso de Shakira, este mecanismo es empleado 17 veces.

\begin{abstract}
Vargas Llosa: No era fácil escribir historias. Al volverse palabras, los proyectos se marchitaban en el papel y las ideas e imágenes desfallecían. ¿Cómo reanimarlos?

Shakira: ¿Cómo es que alguien que nació en Barranquilla (Colombia) ocupa hoy el mismo podio que Newton o Churchill? [...] Sus mentes serán las que cambien el mundo y no puedo sino mirar adelante y pensar cómo será el mundo de aquí a cincuenta años ¿Qué estará sucediendo? ¿Cómo vamos a vivir? ¿Quiénes vamos a ser? ¿Qué retos tendremos que superar?[...] Y me pregunto: ¿qué nos hizo acelerar de tal manera? ¿Cómo podemos seguir acelerando con la misma velocidad? [...] ¿No sería increíble? [...] ¿Cómo vamos a evolucionar en los próximos 10, 20 o 50 años en un mundo en el que se ha empequeñecido mucho, corvintiéndose en un solo vecindario? ¿Cuántas cosas que ahora son impensables serán obvias mañana? ¿Cuántos años va a vivir el ser humano? ¿Cómo se va a estructurar la sociedad? ¿Aún estaremos organizados en parejas? ¿En Comunidades gobernadas por presidentes? [...] ¿Por qué los niños mueren de hambre? [...] Si la educación promueve la paz y la estabilidad mundial, ¿No es eso lo que todos queremos? [...] Sé que la educación es nuestra solución. Y ¿por qué lo sé? Porque lo he visto
\end{abstract}

Las preguntas retóricas son estrategias comunicativas que se utilizan con diferentes intenciones. Lyons (1980:687) diferenciaba entre plantear y formular una pregunta retórica. En el primer caso, generalmente, expresamos una duda; en el segundo, esperamos una respuesta. En el caso de las preguntas aquí recogidas, todas ellas son actos ilocutivos (duda, incertidumbre, curiosidad, etc.) y coinciden en representar una fuerte carga de emotividad. Algunas de estas preguntas, de acuerdo con el sentido más tradicional, no pueden tener respuesta: “ ¿Cómo vamos a evolucionar en los próximos 10, 20 o 50 años?”, “¿Cuántos años va a vivir el ser humano?”, “¿Cómo se va a estructurar la sociedad?”. Otras, sin embargo, son utilizadas como estrategias discursivas para que el hablante pueda dar a conocer la respuesta: “¿por qué lo sé? Porque lo he visto”.

Lo que tienen en común las preguntas retóricas que analizamos es que se trata de un mecanismo utilizado para implicar al oyente. Además, este uso refuerza la carga emotiva del discurso. Como señala Balchi (1994: 343), en ocasiones el hablante 
utiliza este tipo de recurso para expresar un sentimiento mediante una pregunta que no espera respuesta, ya que la respuesta es evidente, no existe o "solo un ser superior y omnisciente podría darla”.

En definitiva, la pregunta retórica es un mecanismo que puede provocar distintos efectos, como la curiosidad, pero, también, la duda y la incertidumbre. Por esta razón, José Blanco no emplea esta forma en su discurso ante el Foro de Nueva Economía, en el que pretende convencer al interlocutor del balance positivo de su gestión. En cambio, Shakira que se dirige a un público joven, con ansias de descubrir cosas y en el que busca que los oyentes imaginen un futuro distinto y mejor, les da pistas, en formas de preguntas, porque considera que es la forma más eficaz de llegar y mantener la atención de ese auditorio.

\subsubsection{Secuencia de cierre}

El buen orador cuida especialmente esta parte, porque sabe que un final con fuerza es imprescindible para que el mensaje llegue y perdure en el oyente. Se trata de provocar una actitud positiva que influya en el auditorio y, en caso de ser necesario, como sucede, por ejemplo, en un discurso político, condicione sus acciones posteriores (ir a votar). Además de convencer al auditorio, el buen discurso debe persuadir. Rúas (2011:91) habla de tres estadios (persuasión, convicción y seducción) y afirma que "la vía racional pretende convencer y la emotiva busca seducir".

Los antiguos denominaban a esta parte peroratio y la definían como "el compendio del discurso entero” (Rodríguez, Romo y Anaya, 2005:178-179). Como el discurso completo depende de los argumentos y de los afectos, distinguían dos partes: la enumeración de los argumentos más importantes y la "agitación de los afectos”. En este sentido Vico en la obra citada apuntaba lo siguiente:

El orador, en esta parte, debe abrir todas las fuentes de la elocuencia; de modo que si alaba, el auditorio no solo alabe, sino dé gracias, se admire y aspire a emular al alabado. Pero si censura, no sólo desprecie, sino también rechace, aborrezca, odie; si aconseja, so sólo levante la esperanza del que delibera, sino que excite la audacia, no solo infunda miedo, sino que provoque el horror...

En estas palabras podemos reconocer la teoría de los actos de Austin. El enunciado que alaba, despierta admiración (acto ilocutivo) y puede provocar en el oyente el deseo de imitar al hablante (acto perlocutivo).

Conviene que el cierre de un discurso sea una paráfrasis del argumento principal del discurso y así ocurre en las secuencias de cierre analizadas, más breves que las otras dos (de inicio y desarrollo). Estas paráfrasis en los discursos analizados son:

Steve Jobs: ¡Sigue hambriento! ¡Sigue alocado!

Shakira: Educación para todos

Mario Vargas Llosa: Tenemos que seguir leyendo, soñando, escribiendo

José Blanco: Haremos lo que hay que hacer sin dejar de ser lo que somos

Ana María Matute: El que no inventa, no vive

Para que el final guarde coherencia con el resto del discurso, el hablante hace uso de los mecanismos que ha empleado en las partes anteriores, pero busca, además, una forma 
específica para terminar. Para conseguirlo, es imprescindible tener un final preparado (Campo Vidal 2011:51) y, a ser posible, impactante. Entre otras cosas, porque tener esa frase preparada sirve para terminar a tiempo. Esto es lo que Cicerón expresaba diciendo que había que terminar “de forma más auténtica y que deje el aguijón”. El hablante tiene que conseguir, más que en ninguna otra parte del discurso, claridad, emotividad y eficacia. En las secuencias de cierre analizadas aparecen los mecanismos que generan coherencia y cohesión en el texto. Sin embargo, cada hablante, de acuerdo con su propio estilo y contexto social, selecciona una forma diferente para terminar.

Ana María Matute comenzaba su discurso con esta idea: "El que no inventa, no vive”. Tras un discurso bien hilvanado, terminaba sintetizando las ideas más importantes y formulando un 'ruego' que termina con un verbo en modo imperativo que indica 'orden':

Con ello solo quiero decir que aquella lucecita azul, aquel virus, no me abandonó nunca. Cuando Alicia, por fin, atravesó el cristal del espejo y se encontró, no solo con su mundo de maravilla, sino consigo misma, no tuvo necesidad de consultar ningún folleto explicativo. Se lo inventó, como la música de papá.

Ahora, tras las deshilvanadas palabras, ojalá haya logrado transmitirles algo de mi alegría, mi gratitud por la distinción que aquí me trae. Y me permito hacerles un ruego: si en algún momento tropiezan con una historia, o con alguna de las criaturas que transmiten mis libros, por favor, créanselas. Créanselas porque me las he inventado.

En el primer párrafo resume lo más importante de su discurso; el segundo comienza con un marcador estructurador del texto que indica el momento ahora; a continuación expresa un deseo, utilizando para ello una interjección ojalá y el modo subjuntivo; por último, expresa un ruego, con el que finaliza.

Entre los modos verbales que el hablante puede utilizar a lo largo del discurso, existe uno, el imperativo, que por su 'efecto discursivo-resultante', 'llamamiento a la acción’, es utilizado también como mecanismo de cierre. Este modo verbal suele ir acompañado de una entonación exclamativa. Esta es la forma elegida para terminar en los discursos de Steve Jobs:i Stay hungry! Stay foolish!” y Shakira: "Ustedes que conducen el coche tienen el acelerador a sus pies. Yo les pido: ipísenlo!”.

Otra forma de terminar un discurso, muy efectiva, consiste en las elecciones de Francia, en mayo de 2012. En el debate celebrado entre los dos candidatos a la Presidencia en Francia (Nicolas Sarkozy y François Hollande), en el periódico El País (domingo 6 de mayo, pág. 4), se leía: "La anáfora o repetición ha marcado tendencia". Esta figura, fue empleada, habilmente, por el candidato socialista, François Hollande para terminar su intervención, cuando repitió, hasta 16 veces: “Moi, President de la République...”

Moi, President de la République, je ne hacer uso de la repetición o ‘anáfora', recurso muy eficaz para subrayar un mensaje. En política, puede tener efectos decisivos, como lo sucedido en serais pas le chef de la mayorité...

Moi, President de la République, je ne traiterai pas avec mon premier Ministre comme un employé...

Entre los cinco discursos analizados en este trabajo es el político José Blanco el que recoge esta figura para terminar su discurso en el Forum de Nueva Economía, cuando dice: 
Por esta razón, tener visión de futuro equivale a potenciar esa conexión, no a negar la evidencia. Eso no es lo responsable y menos que nunca, ahora. Cambian los ciclos económicos. Cambia la tecnología. Cambia la demografía. Y también tiene que cambiar la política. Cambiar para que cada cambio genere el mayor progreso posible en toda la sociedad.

En este caso, el hablante recoge las ideas expuestas y concluye con un marcador indicador de 'causa', por esta razón, que sirve para introducir la conclusión. Además, hace uso de la elipsis: "tener visión de futuro equivale a potenciar esa conexión, no [equivale] a negar la evidencia”.

De los cinco discursos analizados, el más extenso, como ya se ha señalado, es el de Vargas Llosa (6157 palabras). Es también, por tanto, el discurso en el que más temas aparecen: el elogio de la lectura, el recuerdo de su infancia (su madre y otros familiares queridos); su vocación de escritor y sus grandes maestros; la época en la que vive (la democracia liberal); su doble nacionalidad peruana y española; la conquista de América; los nacionalismos; el amor (Patricia)... Y poco antes de llegar a la secuencia de cierre retoma el tema de inicio: la literatura.

Nada ha sembrado tanto la inquietud, removido tanto la imaginación y los deseos, como esa vida de mentiras que añadimos a la que tenemos gracias a la literatura para protagonizar las grandes aventuras, las grandes pasiones, que la vida verdadera nunca nos dará. [...] Porque la nuestra será siempre, por fortuna, una historia inconclusa. Por eso tenemos que seguir soñando, leyendo y escribiendo, la más eficaz manera que hayamos encontrado de aliviar nuestra condición perecedera, de derrotar a la carcoma del tiempo y de convertir en posible lo imposible.

El empleo de palabras y expresiones que se refieren a realidades que se sitúan en polos opuestos, como (caverna/ rascacielos; garrote/ armas de destrucción), y el uso de parejas de contrarios (lo posible y lo imposible), son formas de enfatizar y conseguir, sin perder la coherencia, una fuerte carga de emotividad. La presencia de 'mecanismos de modalización' en este final, con el uso de la perífrasis “tener que + infinitivo”, precedida del 'marcador consecutivo' (por eso), refuerzan el carácter de obligatoriedad que el hablante reclama para estas acciones.

El siguiente cuadro resume los recursos empleados para el cierre en los distintos discursos y los principales efectos conseguidos.

Tabla 3. Recursos y efectos en la secuencia de cierre

\begin{tabular}{|l|l|l|}
\hline DISCURSOS & \multicolumn{1}{|c|}{ RECURSOS } & \multicolumn{1}{|c|}{ EFECTOS } \\
\hline SJ, SH & El imperativo (una orden, una sugerencia) & $\begin{array}{l}\text { Efectividad, emotividad, claridad, } \\
\text { contundencia }\end{array}$ \\
\hline AM & $\begin{array}{l}\text { Un ruego en modo imperativo, precedido de } \\
\text { una condicional }\end{array}$ & Emotividad, claridad, efectividad. \\
\hline JB & Repetición de palabras y frases & $\begin{array}{l}\text { Efectividad, emotividad, claridad, } \\
\text { énfasis }\end{array}$ \\
\hline MV & $\begin{array}{l}\text { Palabras que reflejan realidades extremas. } \\
\text { Perífrasis con valor de 'obligatoriedad' }\end{array}$ & Énfasis, emotividad, eficacia, claridad \\
\hline
\end{tabular}


En todos los casos el hablante conoce la fuerza ilocutiva que tiene la secuencia de cierre. En dos de ellos, los de Steve Jobs y Shakira, se hace uso del modo imperativo: en ambos casos, el interlocutor es un público joven. José Blanco persigue que sus oyentes se vayan con una idea clara y opta por la anáfora o repetición para que la idea perdure; Mario Vargas Llosa, en cambio, emplea el juego de palabras contrarias, en la línea de realidad y ficción de la que trata todo su discurso. Por último, Ana María Matute, después de insistir en la importancia de inventar para vivir, finaliza con un ruego.

\section{Conclusiones}

El sistema formal y abstracto de la lengua y la interpretación que hacemos del uso de ese sistema constituyen dos dominios complementarios que permiten afirmar la existencia de correlación entre 'forma' y ‘función' en los textos analizados y, por extensión, en las manifestaciones discursivas análogas.

El análisis de las estrategias discursivas utilizadas en los discursos protocolarios corrobora la relación existente entre el uso de determinados mecanismos lingüísticos y la recepción exitosa de aquellos. Los datos confirman que estos mecanismos actúan como un resorte en la movilización de reacciones emocionales, empáticas, de proximidad etc. entre los receptores, a pesar de las diferencias notables que se dan en el contexto, en el tema, en el público a quien va dirigido, en la finalidad y, por supuesto, en la personalidad del que habla.

Del análisis se infiere que los cinco hablantes conocen el perfil del oyente y el contexto en el que se va a desarrollar el discurso. El índice de éxito al que nos referimos se ha medido teniendo en cuenta la información obtenida sobre algunos parámetros, como el número de visitas realizadas en las diferentes páginas web, el número y la duración aproximada de los aplausos, los comentarios aparecidos en la prensa, etc.

Detrás de la elaboración de cada uno de estos discursos existe un realizador que conoce las herramientas discursivas que puede utilizar para conseguir transmitir un determinado mensaje a un tipo de oyente. Así pues, estos mecanismos que hemos detectado en los discursos analizados pueden ser utilizados en otros discursos protocolarios con unos resultados similares.

Este trabajo recoge algunas ideas basadas en ejemplos concretos, orientadas a la sistematización de las estrategias discursivas y de sus efectos. De ahí la importancia de conocer estos mecanismos que permiten realizar discursos protocolarios coherentes, emotivos y eficaces, así como las claves para saber descifrarlos en toda su riqueza y extensión.

\section{OBRAS CITADAS}

Austin, John L. (1982): Cómo hacer cosas con palabras, Barcelona, Paidós.

Balchi, Dolores Anunciación Igualada (1994): "Estrategias comunicativas. La pregunta retórica en español”, en Revista Española de Lingüística, 24, 2, págs.329-344.

Benveniste, Émile (1996): Problèmes de linguistique générale I, París, Gallimard. [Trad. Al español: Problemas de lingüística general, México, Siglo XXI, t.I, 1974]

Calsamiglia Blancafort, Helena y Tusón Valls, Amparo (2007): Las cosas del decir. Manual de análisis del discurso, $2^{\mathrm{a}}$ ed., Madrid, Ariel. 
Campo Vidal, Manuel (2011): ¿Por qué los profesionales no comunicamos mejor? Los siete pecados capitales del mal comunicador, Barcelona, RBA Libros.

Cassany, Daniel (1993). La cocina de la escritura. Barcelona. Anagrama.

Cortés Rodríguez, Luis y Camacho Adarve, $\mathrm{M}^{\mathrm{a}}$ Matilde (2003): ¿Qué es el análisis del discurso?, Barcelona, Ediciones Octaedro.

Cortés Rodríguez, Luis y Camacho Adarve, $\mathrm{M}^{\mathrm{a}}$ Matilde (2005): Unidades de segmentación y marcadores del discurso, Madrid, Arco/Libros.

Cortés Rodríguez, Luis (2008): Comentario pragmático de comunicación oral. Un discurso parlamentario, Madrid, Arco/Libros.

Cortés Rodríguez, Luis (2011): "El plano secuencial en los debates. En torno al Estado de la nación. I. El discurso del presidente”, en Círculo de Lingüística aplicada a la comunicación, 46, 3-50, Madrid, Universidad Complutense de Madrid.

Echevarría, Rafael (2011): Ontología del lenguaje, Madrid, J.C. Sáez, editores.

García, Jesús-Nicasio/Marbán, Josefina (2002): Instrucción estratégica en la composición escrita. Barcelona, Ariel Educación.

Halliday, Michael \&Hasan, Ruqaiya (1976): Cohesion in English, Essex, Longman.

Leech, Geoffrey N. (1997): Principios de Pragmática, Logroño, Universidad de la Rioja. (Ed. Original inglesa, Longman, London and New York, 1983). Traducción de Felipe Alcántara.

Lyons. J. (1980): Semántica, Barcelona, Teide.

Montolío, Estrella (2001): Conectores de la lengua escrita, Barcelona, Ariel.

Montolío, Estrella (2006): “Formación en técnicas de comunicación escrita dirigida a ingenieros de informática. El caso de la marcación de la operación textual de la enumeración”, en New Trends in Specialized Discourse Analysis, Maurizio Gotti\&Davide S. Giannoni (eds), Peter Lang AG, Bern, Berlin, Bruxelles, Frankfurt am main, New York, Oxford, Wien, (págs. 248-278).

Portolés, José (2004): Pragmática para hispanistas, Síntesis, Madrid.

Reyes, Graciela (2009): Cómo escribir bien en español, $7^{\mathrm{a}}$ ed., Madrid, Arco libros.

Rodríguez Fernández, Celso; Romo Feito, Fernando; Anaya Revuelta, Inmaculada (2005): Vico. Elementos de Retórica: El sistema de los estudios de nuestro tiempo y Principios de Oratoria, Madrid, Trotta.

Rúas, José (2011): Manual del Candidato Electoral, Madrid, Catarata.

Sanz Álava, Inmaculada (2007): El español Profesional y académico en el aula universitaria. El discurso oral y escrito, Valencia, Tirant lo Blanch.

Searle, John (1969): Speech acts. An essay in the Philosophy of language, Cambridge University Press.

Shel Leanne (2009): Hablar como Obama, (Traducción de Emili Atmetlla), Barcelona, Profit Editorial.

\section{ENLACES}

Blanco, José (2011): http://www.fomento.gob.es/NR/rdonlyres/10478337-C2E5-4A15-9CF75 FC939763A6/98503/11012501IntervencionForumNuevaEconom\%C3\%ADa1.pdf

Matute, Ana María (2011): http://www.elpais.com/elpaismedia/ultimahora/media/201104/27/ cultura/20110427elpepucul_1_Pes_PDF.pdf

Shakira (2009): http://www.youtube.com/watch?v=2yRm3GCZ2U4

Steve Jobs (2005): www.youtube.com/watch?v=uXKku2KYZf0

Vargas Llosa, Mario (2010): http://www.nobelprize.org/nobel_prizes/literature/laureates/2010/ vargas_llosa-lecture_sp.pdf 
